\title{
Co-ownership as a Factor Tertiarization of Postindustrial Society's Economy
}

\author{
Viacheslav A. Perepelkin ${ }^{1}$ \\ 1 Samara State University of Economics, Samara, Russia, Correspondence: Viacheslav A. Perepelkin \\ Samara State University of Economics, 141 Sovetskoi Armii Street 141, Samara 443090, Russia. Email: slavaap@rambler.ru
}

\author{
Doi:10.5901/mjss.2015.v6n6s3p515
}

\begin{abstract}
In the article one of actual tertsiarization reasons is studied as a process of structural transformation of industrially developed economy into post-industrial economy, which is characterized by economic basis formation of a new life activity device which is different from that formation which was observed at the previous agrarian and industrial society evolution stage. The high level of society saturation with material benefits provided with forward rise in labor productivity in production sectors causes not only change in firms, state, households preferences and in favor of immaterial benefits production and consumption but also makes changes to property relations activity. The research objective became objective conditionality justification of economies tertsiarization continuation of advanced countries owing to practice expansion of acquisition replacement in material benefits property by the way of receiving a right of using them in a type of service. Tasks of conditions definition, forms and consequences of production purchases replacement similar to it in consumer services appointment are solved; distinctions between production and services from the point of view of property relations distribution are opened. The conclusion is drawn about inevitability of the economy tertsiarization caused by the present stage of post-industrial societies of property relations transformation assuming the subsequent essential changes in all system of social and market relations.
\end{abstract}

Keywords: possession, replacing services, expenses, production, property, joint use, tertsiarization.

\section{Introduction}

\subsection{Introduction into a problem and its importance determination}

In recent years economic activity provides to the scientists working in the field of economic theory numerous facts of acquisition replacement requiring appropriate judgment in material benefits property by the results of services consumption. If we start from that point that production acquisition in itself does not bring benefit, and only precedes its subsequent use (Levitt, 1972), then the gap between service receiving and its use does not exist in most cases because of the principle of service production and consumption coincidence in time and in space. From the client's point of view other advantage of this service is the opportunity to have temporary access to material benefit which forms rendering service prerequisite (for example, seat on the plane or site in a telecommunication network) without becoming the owner. The client is able to pay service depending on rhythm which is used, i.e. depending on the moment, frequency and duration of its receiving. It leads to products use identification that allows to involve less material benefits and increase wellbeing. Scientists express hope to provide significant increase in natural resources return and saving which are consumed by society due to a wide circulation of services which replace products in the near future. (Melzer-Ridinger, 2009; Hansen, 2009; Hirschl, 2001), however this forecast is not followed by the mechanism description and its realization in practice.

\subsection{The description of existing scientific approaches}

According to Jeremy Rifkin observations who defined in his book name XXI century as "age of access", people often prefer not to possess a benefit but to use it. Instead of price on the market there is a payment for access in a form of membership license, loan agreement or leasing (Rifkin, 2000).

Numerous examples of absence of an ownership right when goods exchange transactions are made (Christopher Lavlok and Evert Gammesson interpret it as a central essential service sign (Lovelock, 2004) visually testify about the emergence of new characteristic economy tertsiarization feature which means that benefit property possession is replaced by the right to use it. Proceeding from bigger orientation of client inquiries and practical benefit which is derived from it the way of benefit consumption without its property, receiving service assumes attention concentration not on 
product properties which is independently existing after its production completion, but on competences which the enterprise has and useful effects derived from them. As an "object of other transaction, than transfer of right possession of material benefit" (Judd, 1964), a demand of "pure" service entirely is defined by usefulness in consumption. If there is a necessity of material benefits use, they act as a prerequisite of rendering service, remaining in property of a proposer. The result of production activity is not substantiated here, client interest requires receiving service.

According to approved conceptualizations, property as an economic category expresses impropriation relations connected with the possibility of a certain benefit use in production and consumption by a certain subject (Zhilinsky, 1998). Moreover, it is supposed economic property realization through obtaining the income. Impropriation relations are an indispensable condition of barter implementation requiring specific subject recognition and subsequent property protection of exchanged benefits. The form of a product is material and immaterial results of works and services, including some means of individualization (in particular, trademarks and trade names) (Novikov, 2008). At the same time, a service itself (if to follow a procedural definition of this concept) is not an object of property, only its result can be alienated and be transferred to a client.

This circumstance formed a basis to use a definition "consumption without property" in regard to services (Scholl, 2011) which recognition involves statement and studying the issue of change of property relations action sphere in postindustrial economy. The service is out of property relations, they extend only on the result received from its granting (Freiling, 2008).

When the content of impropriation relations is revealed, authentic description issue of rights ownership object is extremely important and there are difficulties with a service: first, the result of service becomes obvious only after full completion of its granting, i.e. service disappearance; secondly, confirmation of real existence of a service result, as a rule, is connected with its objectification in this or that form when the service result is expressed through the change of material object properties or actions with participation of the last one (Heidling, 2010). Services participation in barter looks very specific: the ability to produce an effect demanded by a client, it is necessary to make sure that these effects are useful. As only the result is appropriated, there are no ownership services rights, services accumulation is impossible, and direct criterion function of services reproduction is usefulness maximizing received from their consumption. It results in "non-material assets" underestimation as well as immaterial benefits observed in theory and in practice. (Lautenbach, 2004; Grömling, 2009).

\subsection{Scientific hypothesis content}

The property is concept of economy and law when economic content is defining. In this connection it is necessary to consider that legal relations act as reflection of developed rules while economic relations can take place and develop even if the society doesn't know about their existence. So new property relations which are formed in economy are often not fixed legally.

The prospect of coverage reduction if not economic property relations, but ownership right under the influence of tertsiarization development is considerably defined by economic subjects aspiration to reduce the expenses caused by owner functions performance. Along with economic domination over appropriated property it is necessary to undertake its content (in particular, good condition, guarding, taking on risk of making harm to the third parties, death, damage, losses caused by negotiorum gestio). Joint costs of ownership right realization are rather great to lead to optimization actions, and as a way to provide the last one various cooperation forms act in a form of "consumption without property". At the same time, an assessment problem of joint use influence force should be solved as well as a maturity degree of a necessary conditions complex to realize its potential development in the nearest future. The scientific hypothesis of a presented research is in definition of significant factor joint use of present tertsiarization stage.

\section{Method}

As joint use is a synthetic phenomenon uniting economic, social and technical and technological components in itself, its studying requires methods use which are applied in corresponding knowledge areas, in particular, marginal, structurally functional and institutional analysis. Systemacity in research is also reached on the basis of a combination of empirical analysis and theoretical synthesis of joint use characteristics as a tertsiarization factor as a complete system when its structural elements features are revealed. In general research methodology corresponds to neoclassical and institutional theories.

The centripetal forces connected with nstitutionalization inevitably conflict with centrifugal forces which generate economic relations (first of all, property relations) centrifugal forces find their expression in production competition and 
monopolization, circulation, consumption. Out of institutional framework which supposes cooperation in reproduction course private ownership assumes actions to maximize personal benefit without interests of others and also society in general when aspiration to gain income transforms an economic interest into centrifugal force of economic relations. As new alternative to such situation acts cooperation relations establishment which are institutionally still unripe, but economically quite formed in material benefits sharing without their impropriating.

Property recognizing according to Ronald Kouz not resources, not production factors, but rights and duties package which appear in relation to them (Coase, 1990), it is necessary to consider owner interest to expenses optimization which are a result in connection with functions performance. The duty which is opposite to the right to assume expenses is a special analysis subject for a rationally acting owner. Along with acquisition expenses it is necessary to take into consideration transactional expenses, and also use expenses and possession expenses, which are urgent to make decisions about replacing services use. It is known that transactional expenses have rather difficult structure and consist of business contacts establishment expenses connected, for example, with information search, consultation, trips; contracts conclusion expenses, such as negotiating expenses, on reached agreements fixing; execution expenses, in particular production control expenses; control expenses which occur in connection with providing stipulated qualities and terms of information confidentiality, with quantitative and price parameters coordination; adaptation expenses caused by the necessity of happening changes adaptation. (Ahlert, Blaich G., \& Evanschitzky, 2003).

When the purchase is replaced by similar services, transactional expenses, as a rule, increase. The quality inconstancy which is inherent in many services leading to raised experience requirements and producer qualification, in combination with a small offer of services replacing production considerably complicates, and raises a market price. Here the conclusion of many contracts usually assumes bail or the guarantee. Owing to that the principle of coincidence of time and place of their production and consumption concerning the majority of services (uno-actu-prinzip) the client bears additional costs due to holder participation in contract execution. Control expenses are relatively, as you have more and more frequently to monitor the proper condition of the results and physical means, in particular, when lease transaction is carried out. Adjustment costs are significant in long-term relations when, for example, provided software needs regular updating.

The refusal attractiveness from acquiring material goods can be more frequent recourse to services than their replacement product. Widely marked in practice excellence in intensity of real benefits use that are received under employment contract can not only rely on smaller transaction costs when substitute services are implemented but at lower costs and conditions. The nature of their change is variable, the costs of benefit use as the quantity of actions produced with it increases, and their average value is optimized. Purchased products imposes on the owner responsibilities of order, maintenance in good conditions, collection and disposal of generated waste, so when there is rare material benefits use, it's expedient to get it through the service of employment.

Considered to be the permanent acquisition costs, transaction costs and owning costs are weakly related to frequency of use, because of their shared values does not depend on the number of acts committed with the benefit that is in ownership. For example, the size of payments on vehicles insurance costs is not related to the number of trips. Therefore, a rational acting owner who is seeking to maximize utility is often economically interested either in intensive use of his car, or in access to this benefit through an employment transaction, freeing him from a number of liabilities.

With the significant costs of owning a property right use intensification expedience is becoming apparent, limitations imposed by the existing become obstacles for achievement. In addition, a frequency of benefits use increase by one owner has natural limits, which are defined for him by necessity and possibilities of use. Potential for benefit use intensification is more if property relations allow you to extend the range of persons who have access to it on a regular basis. Variants of this include joint alternating access for many users (for example, giving domestic appliances for rent) and joint concurrent access to multiple users (for example, collective trips in one vehicle).

To intensify individual use is primarily return increase from leveraging fixed costs due to increased exploitation of benefits. So, if the owners increase trips, they will have previous values of transaction costs and ownership costs, there are more covered kilometers, while reducing service life of their vehicles. In case of car sharing the same mileage per one person can be provided by fewer vehicles, reducing acquisition costs. Moreover, when sharing car park there is significant savings potential on use costs due to fully loaded vehicles. Thus, the purpose of use intensification is bulkier and harder at mutual implementation, rather than at individual, and the expected benefits seem to be more preferable. 


\section{Results}

Research results was the definition of post-industrial forms of sharing and expansion conditions in the economy.

\subsection{Post-industrial forms of sharing}

The use of modern information and communication technologies, especially the Internet, led to the emergence of postindustrial forms of sharing, for a number of parameters they have greater efficiency compared to traditional forms (in particular rent.) Such postindustrial forms as sharing and sometimes pooling got enough widespread practical application, a general thing in transaction subject is to provide access to the benefit without transferring ownership. The main difference between them is that at sharing agreement you use one type of benefit, while pooling supposes fund creation of several different benefits. Because sometimes requires a high degree of harmonization achieved by consumers, rational organization of mutually advantageous cooperation between them, he got less common.

At the household level by sharing and pooling is not yet sufficiently narrow range of products, consisting mainly of vehicles. The most famous example of a share is created at the end of the XX century in Western Europe carsharing or share cars. understanding irrationality that individual household owned a car mainly stands motionless in the parking lot led to the sharing of one or more cars to a group of people, which has resulted in them not only to share the costs, but also reduce the number of vehicles, the Polohave a positive impact on the environmental situation in the area of transport and accommodation. In the middle 1988, in West Berlin in the search for ways to reduce vehicular traffic (StattAutoBerlin) Community initiative car-pooling found inexpensive and high environmental alternative to the possession of a private motor vehicle. According to Federal Union data of carsharing (Bundesverbandes CarSharing (e). (V), the service was used by 757000 people in 380 cities and communities, which made growth to the previous year to $67.1 \%$ (CarSharing in Zahlen, 2015).

When you select sharing forms the most significant development potential in the application looks in regard to immaterial benefits. Intellectual property objects on a legitimate basis, may come into use in a form of services, which, many of them are by their nature. These opportunities today clearly demonstrate software production, which is the most responsible for this combination of properties. Serving as an alternative to purchasing software system SaaS (software as a service or software as a service) allows to have access to computer programs without a license, giving them payments only if they use them (monthly per minute tariff). Here, unlike buying in property, initial investments are small, as costs of choice, acquisition, adaptation, installation as well as total investments, that is defined by refusal from own expensive equipment for databases, PBX, mail servers, cooling systems networks security systems in the conditions when a user needs a device where software is applied coming from the server. The so-called "cloud technologies" allow to minimize costs of routine maintenance, reconfiguration and equipment repairing. User flexibility increases when choosing a software product at better service, providers have to be to more responsible to customers wishes because it's simple and costs low to apply to competitors. However, establishing good relations with customers is getting more important in SaaS systems, with those clients who risk getting into dependence on a company- services supplier, as well as the fear of data theft hosted on other servers in the absence of complete material and technical and software in IT-field risk falling

\subsection{Conditions for increasing sharing practice}

\subsubsection{Economic conditions for increasing sharing practice}

According to logic of economic efficiency providing the focus of business entity should not be a benefit in property, but on efficiency degree in application. In modern market economy producing and selling products is preceded by needs identification of potential clients, and later building long-term bilateral relations with them. Maintaining competitiveness requires benefits maximization from manufactured product use, it results in consistency of decision-making process on the microeconomic level. Before, not wishing to be alone with a purchased product, customers required an accompanying service, now many people would like to pay only for actual consumption providing other people to take care of other things.

Another condition that the services to be in demand which replacing property possession is drastic reduction of many products life-cycle. For example, much of the product range of electronics and software due to rapid technology progress is fully updated within five years. Today new creativity is able within a short period of time to turn a preceding version of the product into unsuitable for human consumption, an anachronism. The economic expedience of a benefit which is regularly subjected to such innovative reforms with its high cost is questionable, so a variant for use on terms 
and conditions of employment is more preferable.

An effective way to promote regular updating of production program is considered to be reducing costs on building your own equity capital at the expense of attracted one. Getting rid of excess, firms have offices for rent, car-lease, waives part of production capacity through outsourcing. Avoiding long-term investments, they send released funds to the most profitable areas, remaining on present production level as if it's necessary; they have the right to demand from a party providing substitute service a timely update technical-technological content of their proposal. Excellence in flexibility of substitute services over the purchase in property is also expressed in an opportunity to achieve greater utilization of a benefit in time, in particular, at the agreement conclusion on the condition of payment for actual use. However, the client has to accept the loss of full control over a benefit, since it will be used interchangeably with other clients.

Especially when complex technical device is sold in property manufacturers are interested in regular updating of a consumers model range, as a product substitution for the better one increases marketing area. Extending product life cycle through some of its components upgrading, looks less profitable in the end, a consumer has to replace a functional laptop because of liquid crystal panel is damaged, or a pair of keys don't work. If, for example, the company Xerox is shifting from copier sales to their lease, service and complement where it is necessary. The priority for this company becomes an output of long-lasting copiers consuming little toners. "Consumption without property" encourages manufacturers to life cycle lengthening, providing the possibility to intensive use, to better technical services, to high raw material and energy efficiency, security and compactness, low-cost utilization. Direct involvement in the process of product applying makes a manufacturer fuller and better take into account the diverse interests of consumers -from economic to environmental - which promotes the growth of socio-economic efficiency.

Thus, another requirement for buying-selling benefit replacement by use services is manufacturer-leaser direct interest in manufacturing durable, repairable, economical products. This fact is especially important for forms of benefitsharing application, in which opportunities to intensify this process are very high. The simultaneous or alternating use of a benefit (respectively, collective TV watching or collective using washing machine) when you are able to bring a number of sharing agreements of economic and non-economic benefits, such as separation of a purchase price, fixed costs and repairing risk for multiple users, reducing load per unit on environment due to lower quantity of benefits for a fixed amount of work (group of craftsmen, acquired a metal cutting machine for sharing). It should be noted here that the intensification of benefits use is expedient as long as the marginal costs will not exceed marginal revenues. Thus when time period increases, employment intensity of use tends to decrease.

\subsubsection{Social conditions of sharing practice extending}

Condition for recognition of substitute property services, along with the existence of economic incentives and the availability of necessary logistical and physical conditions for their use, is making major changes in established cultural practices of consumption. Choice in favor of those or other benefits is based on social patterns of consumer behavior, adopted or rejected by a specific individual depending on his membership in a particular social group. Tornstein Veblen noted a desire in people to demonstrate a sense of self-importance and to confirm their social status through "demonstrative consumption" (Veblen, 1919). Owned things are more suitable for personal importance expression than coming in sharing mode, appearing and disappearing services. It's naive to ignore social side of consumption, focusing exclusively on functionally individual attitude to a product, considering it as a carrier of economically measured value. There are strong social stereotypes that reflect the emergence, stabilization and decay patterns of consumption, one of which is property preference. Continuation of shift from production to services creation supposes transformation of tangible benefits based on consumption, private property institution, collective action and social partial routine, sociallyseparated symbologies into the condition, which is more appropriate to system of values of emerging postindustrial society.

If a consumption practice connected with property is expressed in actions that are considered individually, then getting substitute property services supposes more or less consistent sharing. Visiting libraries, trips by trains, washing in self-service laundries that are familiar from ancient times, today are continuing in sharing forms of consumption, based on use right acquisition. An essential condition for widespread adoption of sharing practice of tangible benefits, access to which is provided in a form of services, support, education social communities who possess competencies concerning correct and understandable explanation of transition to substitute services use and establishing relevant socio-cultural consumption samples. To get widespread adoption of substitute property services should cease to be an individual solution to problems it became a simulated social phenomenon, positively assessed and supported by many selforganizing consumer groups. Only then sharing ownership of a use right will become attractive to the main part of economic entities which currently give a priority to free access to a benefit at any time and highly prestigious possession 
before addressing to potentially advantageous, but inhabitable substitute services. To help overcome last invisible barrier deeply rooted in public mind, and often irrationally played in economic relations, feeling the need of material benefits is really in a position to already existing hybrid forms of products and services that mitigate contradiction between ideas about a product as an object property and as means to get benefit in the first place.

\section{Discussion}

Independent promising research line of sharing appear to be studying the impact of its development on structure transformation of ownership relations in post-industrial society. The provision that wealth is in use, not ownership was suggested by Aristotle (Aristotle, 2007). The idea which seems to be banal about buying the product by an end-user not to own them, and to benefit from it, in application to modern conditions it could cause doubts in rationality of property institution maintenance in a form in which it was formed to present moment. The last is equal to revolution in the public mind, assuming rethinking some of fundamental provisions of economic science and practice. So, if a useful consumer effect comes on the first place, then pricing should be based not only on production costs, but on correlation of total costs and benefits for the whole period of his normative use. Postindustrial sharing forms lead to institutionalization of sustainable new type of consumer groups, self-organizing on the base of practical idea implementation of a user replacing.

With a number of economic, social and technological conditions sharing demonstrates a significant potential of sharing applications. Based on the principle of integrated efficiency benefits, for example, many airlines, instead of purchasing planes, the price of which is less than $1 / 5$ of all operating costs over all exploitation period, take them in lease (Dunkin and Ivanova, 2004). Moreover, from a functional perspective, the service has an obvious advantage over real good - its user does not need to complicate his life with property on the product but only in properties use of the latter. Therefore, at market transaction preference is more often given not to purchasing a finished product but to mutual actions to obtain a similar result of services consumption.

\section{Conclusion}

Practice of purchasing physical goods in replacement property is becoming more widespread and similar to the consumption of services received, along with economic benefits is determined by social and environmental interests of consumers and producers. In a densely populated environment of mega-cities voluntary self-organization forms spontaneously appear aimed at ensuring economically efficient, socially responsible, clean sharing. Expansion of postindustrial sharing forms can not only define the content of economies tertiarization present stage of advanced societies, but also lead to structure transformation of ownership relations. The tradition of owning property is strong in society, but following it is broken in case of joint use of substitute services.

\section{References}

Ahlert, D. Blaich, g., \& Evanschitzky, h. (2003). Systematisierung von Dienstleistungsnetzwerken. In M. Bruhn, B. Strauss (Ed). Dienstleistungsnetzwerke (pp. 31-59). Wiesbaden: Gabler.

Aristotle. (2007). Rhetoric. M .: Labyrint.

Carsharing in Zahlen (2015). Bundesverband CarSharing. Retrieved from http://www.carsharing.de/alles-ueber-carsharing/carsharingzahlen.html

Coase, R. (H). (1990). The Firm, the Market, and the Law. Chicago: the University of Chi-cago Press.

Dunkin, A. (A) . \& Ivanova N. I. (Eds.). (2004) the Innovative economy. M .: Science.

Freiling, j. (2008). Auf dem Weg zu einer "Dienstleistungstheorie": das Zusammenspiel kollektiver Fähigkeiten und individueller in aktueller Theorienentwicklungen Kontext. In: h. Gersch (ed.), Wirkungsbeziehungen Fähigkeiten und individuellen zwischen kollektiver Kompetenz (pp. 199-130). München \& Mering: Rainer Hamp Verlag. -S. 199-130.

Grömling, m. (2009). Megatrends und Globale Perspektiven der deutschen Industrie. M. Haß-Köln: Deutscher Instituts-Verlag GmbH.

Hansen, h. (2009). Grunderfolgs wissenintensiver Dienstleister. Wiesbaden: Gabler.

Heidling, e. (2010). Produktion Integration als Dienstleistung mit Zukunftschance. München und Mering: Reiner Hampp Verlag.

Hirschl, b. (2011). Produktnutzung: sozial Nachhaltige ökonomische und ökologische Bedingungen-Vorteile alternative Konsumformen. Berlin: Edition Sigma.

Judd, R.C. (1964), The case for redefining services. Journal of marketing, 28, 58-59.

Lautenbach, n. (2004). Tertiarisierung und Informatisierung in Europa. Frankfurt am Main: Peter Lang.

Levitt, t. (1972, September-October), Production-line approach to service, Havard-Business Review, 41-52.

1975, c. \& Gummesson, e. (2004). Whither services marketing? Journal of service research, 7, 20-41. 
Melzer-Ridinger, r. (2009). Dienstleistung und Produktion. Heidelberg: Physica-Verlag.

Novikov, a. b. (2008). Administrative process in the mechanism of customs regulation of Russian Federation. Saint Petersburg.: Info-da. Rifkin, j. (2000). The age of access. New York: Wintage Books.

Scholl, g. (2011). Nachhaltiger Konsum ohne Eigentum. Ökologisches Wirtschaften in 2. (pp. 30-34). Berlin: Oekom Verlag.

Stampfl, N.S. (2011). Die Zukunft der Dienstleistungsökonomie. Momentaufnahme und Perspektiven. Berlin, Heidelberg: SpringerVerlag.

Veblen, t. (1919). The Place of Science in Moderrn Civilization and Other Essays. -New York: Huebsch.

Zhilinsky, s. e. (1998). Enterpreneurial law (legal basis for enterpreneurial activity). M.: NORMA. 